\title{
Vaccine tests to begin in Ebola countries this year
}

\author{
Anne Gulland
}

London

Trials of two candidate Ebola vaccines have been fast tracked and will now begin in west Africa in December, the World Health Organization has said.

A meeting of officials from the affected countries, donors, manufacturers, funding agencies, and civil society

representatives met on 23 October and agreed that clinical trials could begin in December, bringing the trial start date forward a month.

The two vaccines are cAd3-ZEBOV, a chimpanzee derived adenovirus vaccine developed by GlaxoSmithKline in conjunction with the US National Institute of Allergy and Infectious Diseases, and rVSV-ZEBOV, developed by the Public Health Agency of Canada and now licensed to a US company, New Link. ${ }^{1}$ Phase one safety and immunogenicity trials are currently taking place in the United Kingdom, United States, and Mali and will soon begin in Germany, Switzerland, Gabon, and Kenya.

Marie-Paule Kieny, the World Health Organization's assistant director general for health systems and innovation, told a press conference on 24 October that the two drug companies were ramping up vaccine production so that hundreds of thousands of doses would be available for testing, initially in Liberia, by the beginning of December. "As we accelerate in a matter of weeks a process that typically takes years we are ensuring that safety remains a top priority," she said.

The vaccines will be tested on healthcare workers and other groups, and some will be given a placebo, as this was the best way to test whether the vaccine was effective, she said.

On 21 October WHO said that only a few thousand doses of the vaccine were available and that trials would not start in the three worst affected countries until the beginning of next year, but Kieny said that the situation was changing rapidly. "There is strong mobilisation of all the countries and the manufacturers, and the situation is changing from week to week," she said.

Médecins Sans Frontières, the aid agency leading the response to the crisis on the ground, has agreed to create a vaccine fund, and traditional donor countries have also made pledges. The Gavi Alliance, which funds vaccines in the developing world, will take a funding proposal to its board in December. Exact figures have not been given, but at an earlier press conference Kieny said that the vaccines would cost hundreds of millions of dollars.

WHO's latest situation report on the virus in the three worst affected countries of Sierra Leone, Liberia, and Guinea, published on 22 October, said that there have been 9936 cases of the disease, including 4877 deaths. All districts in Sierra Leone have now reported a case of the disease.

Meanwhile Mali, which has a long border with Guinea, has announced its first case of Ebola virus disease. A 2 year old girl, whose mother died from the disease after returning from Guinea, tested positive earlier this week. The case was identified near the country's border with Senegal, where an Ebola preparedness team was in situ, said Kieny. "We all hope that they will be able to control the spread of this new imported case," she said.

Last week WHO identified Mali as one of 15 countries in Africa on high alert for the disease. ${ }^{2}$

WHO has also reiterated that there should be no general ban on international travel or trade with the affected countries. It said that exit screening, including as a minimum a questionnaire, temperature monitoring, and an assessment of the risk of whether any fever was due to Ebola, was an important way to contain the outbreak. WHO is sticking to its line that entry screening is not necessary but said that countries where it has been implemented, such as the United Kingdom, should share what they have learnt.

Keiji Fukuda, WHO's assistant director general for health security and environment, said that screening seemed to have a deterrent effect on travellers. "One of things that was noted was that simply knowing that screening is going to occur anywhere, whether it's exit or entry screening, [has] a psychological impact," he said.

Gulland A. Ebola drug trial is to start next month. BMJ 2014;349:g6436.

Gulland A. Fifteen countries are at risk of Ebola outbreak, says WHO. BMJ 2014;349:g6305

Cite this as: BMJ 2014;349:g6466

๑ BMJ Publishing Group Ltd 2014 